\title{
Thermal Oxidation Preparation of Doped Hematite Thin Films for Photoelectrochemical Water Splitting
}

\author{
Song Li, Jiajia Cai, Yudong Mei, Yuping Ren, and Gaowu Qin \\ Key Laboratory for Anisotropy and Texture of Materials (MoE), Northeastern University, Shenyang 110819, China \\ Correspondence should be addressed to Gaowu Qin; qingw@smm.neu.edu.cn
}

Received 10 November 2013; Revised 13 December 2013; Accepted 10 January 2014; Published 2 March 2014

Academic Editor: Shahed Khan

Copyright (C) 2014 Song Li et al. This is an open access article distributed under the Creative Commons Attribution License, which permits unrestricted use, distribution, and reproduction in any medium, provided the original work is properly cited.

\begin{abstract}
Sn- or Ge-doped hematite thin films were fabricated by annealing alloyed films for the purpose of photoelectrochemical (PEC) water splitting. The alloyed films were deposited on FTO glass by magnetron sputtering and their compositions were controlled by the target. The morphology, crystalline structure, optical properties, and photocatalytic activities have been investigated. The SEM observation showed that uniform, large area arrays of nanoflakes formed after thermal oxidation. The incorporation of doping elements into the hematite structure was confirmed by XRD. The photocurrent density-voltage characterization illustrated that the nanoflake films of Sn-doped hematite exhibited high PEC performance and the Sn concentration was optimized about 5\%. The doped $\mathrm{Ge}^{4+}$ ions were proposed to occupy the empty octahedral holes and their effect on PEC performance of hematite is smaller than that of tin ions.
\end{abstract}

\section{Introduction}

Since the pioneering work of Fujishima and Honda who demonstrated the photocatalytic splitting of water using $\mathrm{TiO}_{2}$ photoanode [1], semiconductor photocatalysis has drawn considerable academic and commercial interests due to the capability of producing hydrogen energy from water $[2,3]$ and converting $\mathrm{CO}_{2}$ to hydrocarbon fuels using sunlight [4]. Unfortunately, $\mathrm{TiO}_{2}$ absorbs only a small fraction of solar irradiation (less than 5\%) due to its wide band gap. Though much research work has been deployed [5], the efficiency of $\mathrm{TiO}_{2}$ in visible light range is still not sufficiently high and problems such as instability may arise as a result of modification. Therefore, photoelectrode films comprised of nanostructured semiconductors with smaller intrinsic band gap are highly demanded and increasing attentions have been paid to this field.

With a proper band gap of about $2.1 \mathrm{eV}$, hematite $(\alpha$ $\mathrm{Fe}_{2} \mathrm{O}_{3}$ ) can absorb a much larger proportion (about 40\%) of visible light irradiation in solar spectra. Moreover, other merits such as good photochemical stability in basic solutions [6], nontoxicity, and large abundance allow hematite, one of the most promising candidates for highly efficient photoelectrode materials [7-9]. However, the reported photoelectrochemical (PEC) conversion efficiency is much lower than the theoretical level [10] because of small electron mobility, high resistance, and short minority carrier diffusion length. Accordingly, recombination of photo-induced electron-hole pairs occurs easily before the charges can reach the corresponding electrode to initiate redox reactions.

To address the problem, two strategies were adopted to enhance the PEC performance of hematite films, that is, morphology control of hematite nanostructures $[9,11-$ 13] and elemental doping [14-20]. By controlling the film morphology, the length scale of hematite structures is tuned comparable to the hole transport length. Doping with metal atoms can improve the mobility of charge carriers of hematite, which has been demonstrated by theoretical and experimental works [21]. Specifically, introducing tetravalent ions such as $\mathrm{Ti}^{4+}$ and $\mathrm{Sn}^{4+}$ into hematite lattice may contribute to the conductivity because the extra valence electron can easily be excited to the conduction band. Among the many investigated doping elements, $\mathrm{Sn}$ is shown to be the highest promising element. Atomic diffusion from FTO underlayers [19] or solid-phase reaction [18] has been proposed for doping hematite films with $\mathrm{Sn}$ and improved photocatalytic activity was observed. However, these methods generally require high temperature which can diminish the conductivity of the FTO 


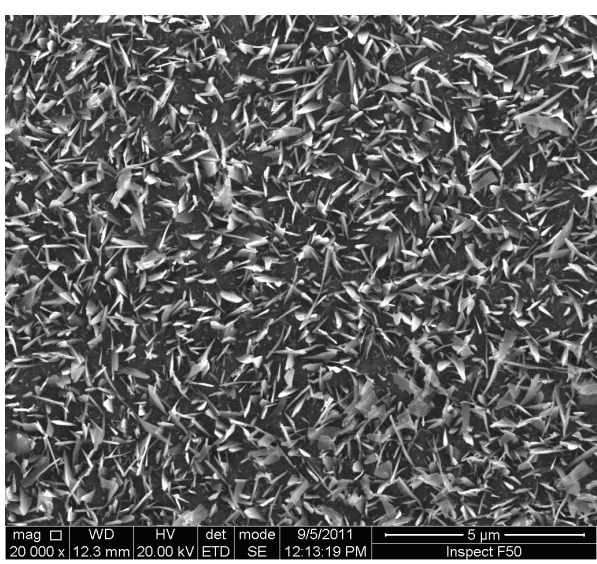

(a)

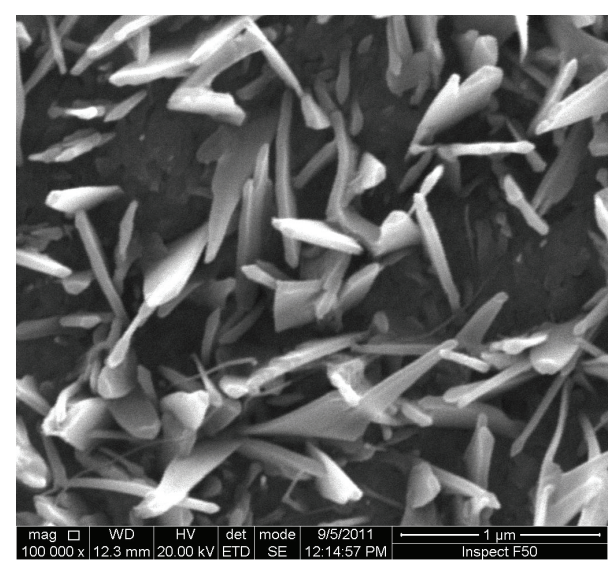

(b)

FIGURE 1: SEM images of iron oxide films of nanoflakes. (a) Low magnification and (b) high magnification.

or ITO glass. Furthermore, heating hematite may produce magnetite inclusions on the surface [22] and then harm the photocatalytic performance of hematite.

It is very advantageous to combine the desirable benefits of morphology control and elemental doping, as has been done in doped hematite one-dimensional nanostructures [19, 23]. Motivated by the previous work on hematite photoanode, this study reports a simple and large area scalable method for the preparation of hematite nanoflake films by heating iron films in air at relatively low temperature $\left(375^{\circ} \mathrm{C} \sim 450^{\circ} \mathrm{C}\right)$. Sn or Ge was cosputtered along with iron on FTO glass to prepare the doped hematite films. This method can easily be extended for the fabrication of hematite nanoflake films doped by most metal elements. The effect of doping on the PEC properties of hematite films was also investigated.

\section{Experimental}

The iron alloy films were deposited on conductive fluorinedoped tin oxide (FTO) glass substrate by DC magnetron sputtering technique and the target was a commercial available iron disk with chips of desired doping element pasted on the surface. The concentration of doping element $(M, M=S n$ or $\mathrm{Ge})$ is defined as $\mathrm{M} /(\mathrm{M}+\mathrm{Fe})$ mole ratios were tuned by the relative areas of the pasted chips [24] and determined by EDS. Prior to sputtering deposition, FTO substrates were sonically cleaned using acetone, ethanol, and deionized water each for $10 \mathrm{~min}$ in that sequence. Doped hematite films were obtained by placing the sputtered alloy films in a tube furnace at $375^{\circ} \mathrm{C}$ to $450^{\circ} \mathrm{C}$ in air for a period of $10 \mathrm{~h}$.

The morphologies of the as-prepared hematite films were examined by scanning electron microscopy (SEM, JEOL JSM-7100F). X-ray diffraction (XRD, Philips X'Pert PRO) patterns were obtained using $\mathrm{Cu} \mathrm{K}_{\alpha}$ radiation $(\lambda=$ $0.15406 \mathrm{~nm}$ ). The photocurrent-voltage behaviors were measured in a three-electrode configuration with $1.0 \mathrm{M} \mathrm{NaOH}$ solution as electrolyte. A Pt plate and a $\mathrm{Ag} / \mathrm{AgCl}$ electrode were used as the counter and reference electrodes, respectively. The potential of photoelectrode was controlled by a potentiostat (Zahner IM6) and the scan rate was $10 \mathrm{mV} \mathrm{s}^{-1}$. The samples with area $1.0 \mathrm{~cm}^{2}$ were illuminated under a $300 \mathrm{~W}$ xenon lamp using an AM 1.5 G filter (Mega-9, Shanghai).

\section{Results and Discussion}

Iron oxide nanoflakes grew on FTO substrate after the alloyed films were thermally oxidized in air. Figure 1 shows typical SEM images of as-grown nanoflakes of hematite. Clearly, large area and uniform film of hematite nanoflakes with a thickness of $\sim 50 \mathrm{~nm}$ formed. By investigating the thermal oxidation of iron foils, Wen et al. found that morphology of oxidized iron oxide transition from nanoflakes to nanowires when the treatment temperature was increased over $700^{\circ} \mathrm{C}$ [25]. Noticing that the rapid heating rate could induce porous structure of the oxide film [26], a slow heating rate of $10^{\circ} \mathrm{C} \mathrm{min}^{-1}$ was adopted in this work. Furthermore, for photoelectrochemical applications, low temperature treatment of samples is necessary since the high temperature may deteriorate the conductivity of ITO or FTO underlayers.

The nanoflakes films of $\alpha-\mathrm{Fe}_{2} \mathrm{O}_{3}$ doped with $\mathrm{Sn}$ or Ge were translucent and had a color of red brown. Figure 2 shows the optical absorption spectra of the iron oxide films obtained after annealing at $400^{\circ} \mathrm{C}$. As reported in the literature, the onset of absorption occurred at about $600 \mathrm{~nm}$ for the undoped hematite films. For Sn-doped samples, the light absorption properties are broadly similar to the undoped in the visible range. In previous reports, the influence of Sndoping on light absorption of hematite is ambiguous and controversial. In Jang et al's work, the light absorption of $4 \%$ Sn-doped hematite film decreased slightly [27]. Some other researchers reported remarkable increase in light absorption for Sn-doped hematite films which were results of atomic diffusion from FTO at high temperatures (over $600^{\circ} \mathrm{C}$ ) $[28$, 29]. In contrast, Ge-doping has more apparent effect on the light absorption of hematite films. At higher doping Ge concentrations (over 6\%), the light absorption gets enhanced apparently, especially in the region of long wavelength. 


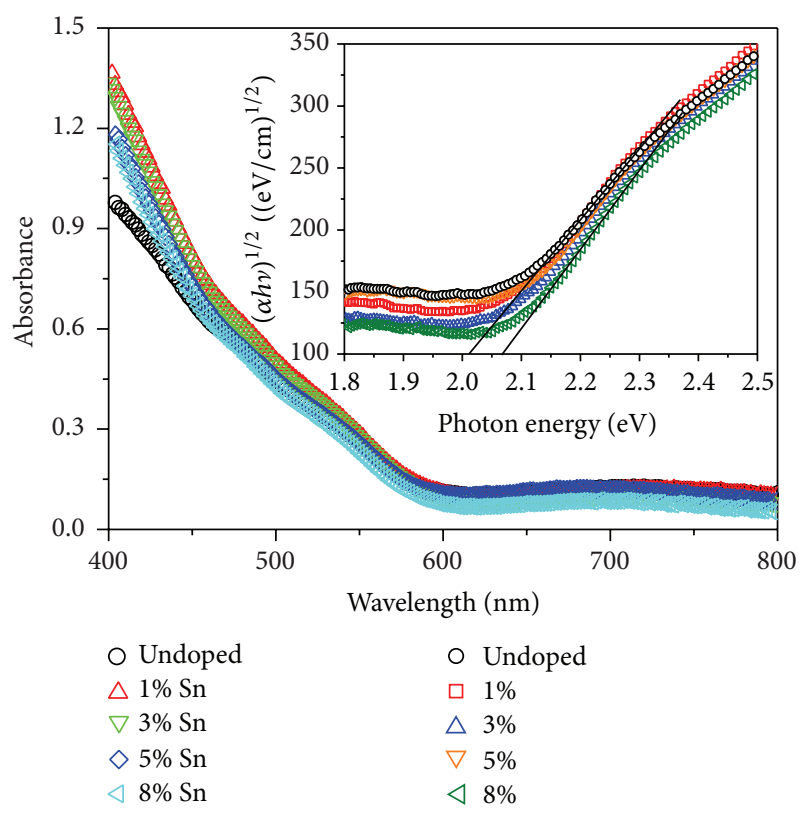

(a)

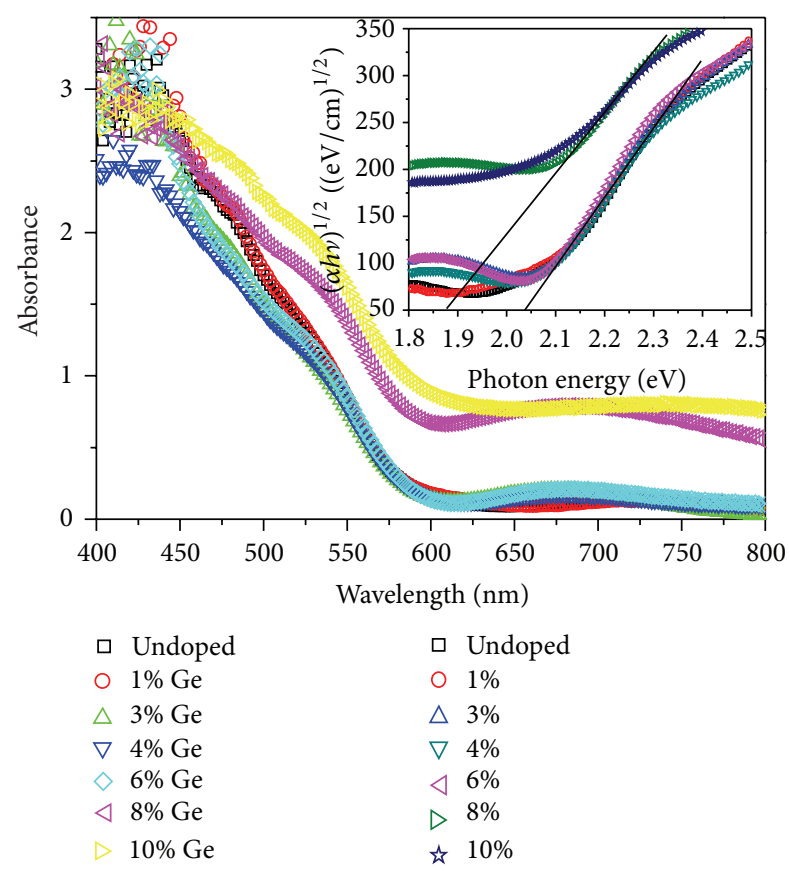

(b)

FIGURE 2: Optical absorption spectra (absorbance versus photon energy) for thermal oxidized hematite films doped with (a) Sn and (b) Ge. Inset: the corresponding Tauc plot.

Band structures of semiconducting materials have significant impacts on their photoactivities. The optical band gap $\left(E_{g}\right)$ can be determined by the Tauc equation [30] below:

$$
\alpha h v=A\left(h v-E_{g}\right)^{n},
$$

where $A$ is a constant, $h v$ is the energy of the impinging photon, and $n$ is a constant depending on the type of transition ( 2 for allowed indirect and $1 / 2$ for allowed direct transition). In inset of Figure 2, $(\alpha h v)^{1 / 2}$ is plotted against $h v$ and the linear region is extrapolated to obtain the value of band gap. As expected, the Tauc plots reveal that Sndoping or low-concentration Ge-doping $(<6 \%)$ does not change the band gap of hematite by exhibiting indirect transitions at $2.04 \pm 0.03 \mathrm{eV}$. However, the indirect band gap of hematite films decreased to about $1.88 \mathrm{eV}$ when the mole ratio of $\mathrm{Ge} /(\mathrm{Ge}+\mathrm{Fe})$ exceeds $6 \%$, suggesting an improved photoelectrochemical activity. The band gap narrowing may be a result of lattice constant change due to iron atom substitution [31], as explained later.

The XRD patterns of Ge-doped hematite films on FTO substrates after thermal oxidation are displayed in Figure 3(a), which clearly shows the highly crystalline nature of the films prepared by this method. All peaks that are not assigned to tin oxide from the substrate were indexed to the rhombohedral phase of hematite (ICDD no. 79-0007). No impurity peaks from other iron oxide or Ge oxide are present in these patterns. Raman spectra in Figure 3(c), which give surface structural information, also confirm the introduction of Ge into hematite structure. To demonstrate the doping effect on hematite structure, an expanded view of the major (104) peak of hematite and (110) peak of $\mathrm{SnO}_{2}$ is shown in panel Figure 3(b). Obviously, the peak position of (104) plane of hematite for $6 \%$ and undoped is virtually the same, which is inconsistent with reported XRD measurement at low $\mathrm{Ge}$ contents [32]. When the Ge doping ratio exceeds $8 \%$, a shift toward lower angle was observed for the (104) peak positions and the extents of the shift are roughly the same. The result is unexpected because the dissolved $\mathrm{Ge}^{4+}$ ions are generally supposed to substitute the $\mathrm{Fe}^{3+}$ ions in the lattice structure [33] and the ionic radius of $\mathrm{Ge}^{4+}$ is slightly smaller than that of $\mathrm{Fe}^{3+}$. We propose that Ge dopant can take both the substituting $\mathrm{Fe}^{3+}$ and interstitial sites in the corundum structure. And the probability of taking the interstitial sites grows with doping levels. XRD refinement technology revealed that the tin ions in $\mathrm{Sn}_{x} \mathrm{Fe}_{2-2 x} \mathrm{O}_{3-x}$ may fully [34] or partially [35] occupy the octahedral hole positions rather than substituting the iron ions. The ionic radius of $\mathrm{Ge}^{4+}$ is smaller than that of $\mathrm{Sn}^{4+}$. Therefore, it is highly reasonable that $\mathrm{Ge}^{4+}$ also occupy hole positions as $\mathrm{Sn}^{4+}$ does. In this case, the change in lattice parameter is consistent with optical properties as mentioned above.

The photocatalytic activity of hematite films was evaluated by measuring the dependence of photocurrent density on applied potential in a three-electrode electrochemical cell using a $1.0 \mathrm{M} \mathrm{NaOH}$ solution $(\mathrm{pH}=13.6)$ as electrolyte. The measured potentials versus $\mathrm{Ag} / \mathrm{AgCl}$ were converted to the reversible hydrogen electrode (RHE) scale according to the following equation:

$$
E_{\mathrm{RHE}}=E_{\mathrm{Ag} / \mathrm{AgCl}}+0.059 \mathrm{pH}+E_{\mathrm{Ag} / \mathrm{AgCl}}^{\circ},
$$

where $E_{\mathrm{Ag} / \mathrm{AgCl}}^{\circ}=0.1976 \mathrm{~V}$. Shown in Figure 4 are the $J$ $V$ curves obtained from the doped hematite films. A strong dependence of the photocurrent density on the doping element and doping concentration was observed. And Sn doping is more favorable for enhancing the photoelectrochemical 


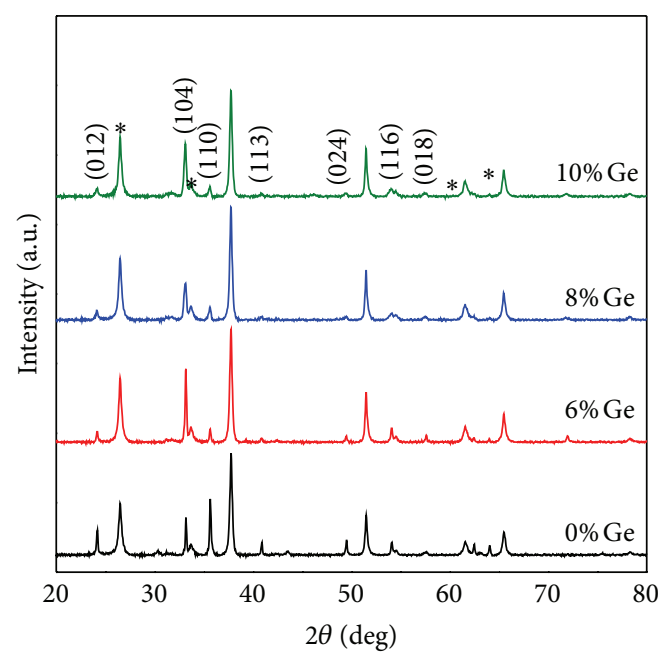

* $\mathrm{SnO}_{2}$

(a)

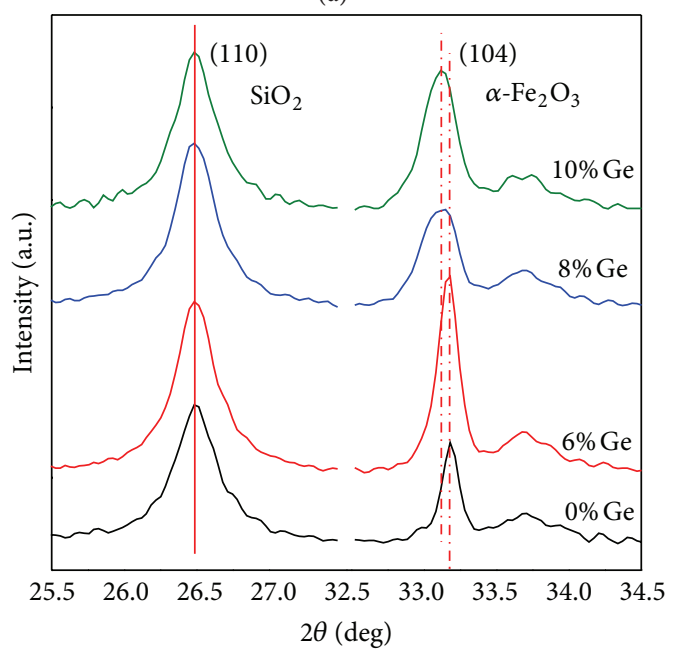

(b)

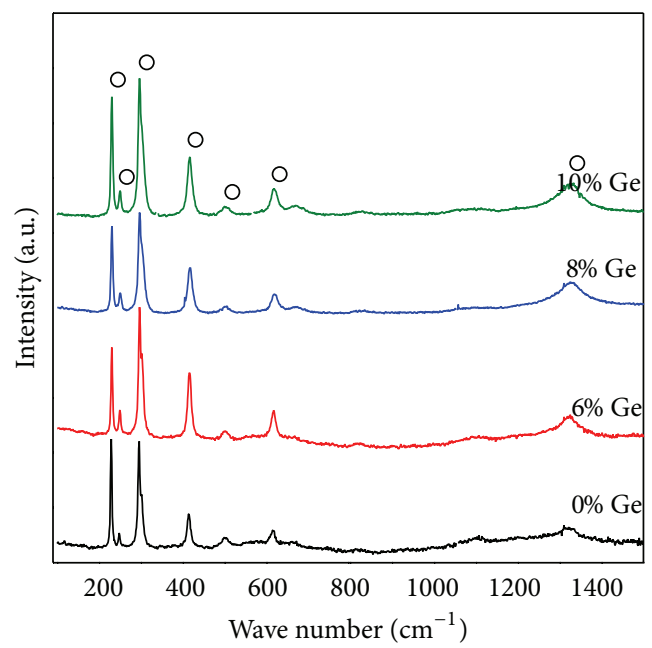

$\mathrm{O} \mathrm{Fe}_{2} \mathrm{O}_{3}$

(c)

FIGURE 3: (a) Full and (b) extended XRD profile of hematite films with various $\mathrm{Ge}$ concentrations. The peaks labeled with $*$ are from FTO substrate. (c) Corresponding Raman spectra of samples in (a).

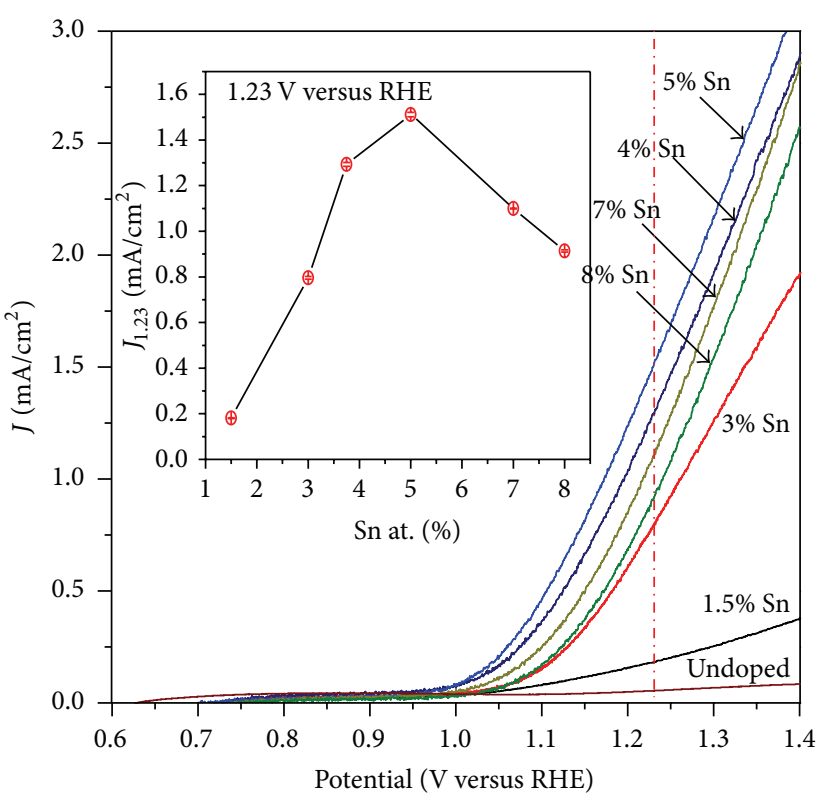

(a)

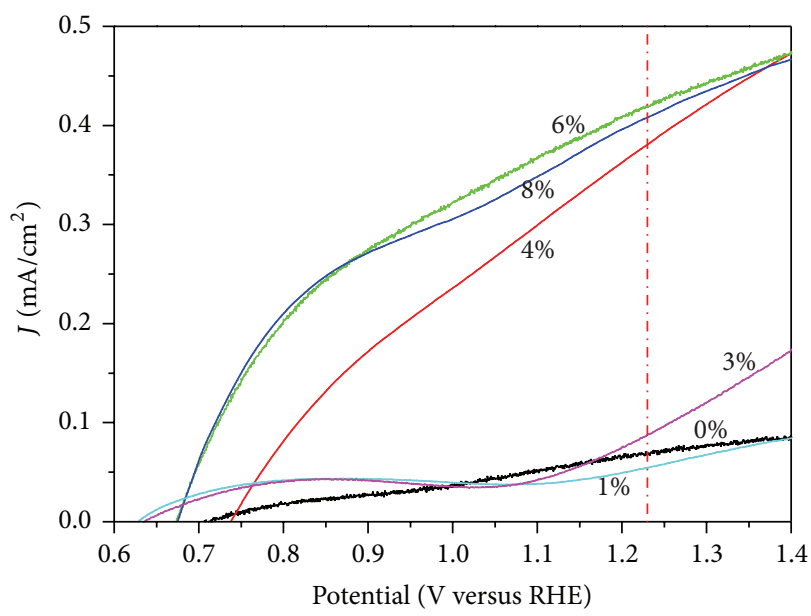

(b)

FIGURE 4: Photocurrent density versus bias potential of (a) Sn- (b) Ge-doped hematite photoanodes. All samples were measured in $1.0 \mathrm{M} \mathrm{NaOH}$ electrolyte under $300 \mathrm{~W}$ Xe lamp irradiation with an AM 1.5 filter. Inset of (a) the photocurrent density at $1.23 \mathrm{~V}$ versus RHE as a function of $\mathrm{Sn}$ concentration.

response of hematite. By acting as electron donors, the doping tetravalent ions $\left(\mathrm{Sn}^{4+}\right.$ or $\left.\mathrm{Ge}^{4+}\right)$ can induce reduction of $\mathrm{Fe}^{3+}$ to $\mathrm{Fe}^{2+}$ which can provide extra 3D electrons and further improve the electrical conductivity [32]. Experimental measurements also proved that doping of $\mathrm{Sn}$ or Ge can increase the electron density and significantly lower the electronic resistivity (by orders of magnitude) of hematite $[18,19,36]$. Thereby, the recombination of photogenerated charge carriers is reduced with doping levels and higher photocurrent is obtained as a result. The discrepancy between the two doping species comes from their ionization tendency and abilities of trapping electron carriers [33]. 
Moreover, a nonmonotonic doping dependence of the photoactivity performance was observed for either Sn or Ge doping. A high photocurrent density of $1.51 \mathrm{~mA} \mathrm{~cm}^{-2}$ at $1.23 \mathrm{~V}$ versus RHE, which is over 30 times higher than the undoped sample, was found for optimized Sn-doping sample. In the case of $\mathrm{Ge}$ doping, the highest photocurrent density at $1.23 \mathrm{~V}$ versus RHE is $0.42 \mathrm{~mA} \mathrm{~cm}^{-2}$, merely 8 times higher than that of undoped. The doping concentration dependence arises from two possible reasons. Firstly, the $\alpha-\mathrm{Fe}_{2} \mathrm{O}_{3}$ lattice has a limited tolerance for the doping atoms [32]. Thus, the doping atoms aggregate inside the crystal with rise of doping levels and their contribution to local extra valence electrons is reduced. The second phase may occur and decrease the charge transfer at high doping concentrations. Secondly, high doping concentration causes severe lattice distortion and compensates the positive effects of doping on charge mobility. Ge doping shifts the photocurrent onset to less positive potentials, which could be caused by the change of the hematite-electrolyte interface. The reason remains open but the finding has great hint for practical application, which means a faster kinetics of the photohole reaction with water.

\section{Conclusions}

In summary, we have developed a facile growth and doping method for $\alpha-\mathrm{Fe}_{2} \mathrm{O}_{3}$ nanoflake array films which can be operated at relatively low temperature $\left(<500^{\circ} \mathrm{C}\right)$. The procedure comprises steps of magnetron sputtering of alloyed thin film and thermal oxidation treatment. The doping concentration of the films can be adjusted by varying the target composition during the sputtering. The correlation between the photocatalytic activity for splitting water and doping concentrations of $\mathrm{Sn}^{4+}$ or $\mathrm{Ge}^{4+}$ has been established. The photocurrent of hematite film is enhanced by doping $\mathrm{Sn}$ and the photocurrent onset is shifted to lower potentials by Ge doping. This method can be used to fabricate many other doped metal oxide films with designed chemical composition and morphologies.

\section{Conflict of Interests}

The authors declare that there is no conflict of interests regarding the publication of this paper.

\section{Acknowledgments}

This work was supported by the NSFC under Grant no. 51002026 and the Fundamental Research Funds for the Central Universities (nos. N110410002, N110810001, and N100702001).

\section{References}

[1] A. Fujishima and K. Honda, "Electrochemical photolysis of water at a semiconductor electrode," Nature, vol. 238, no. 5358, pp. 37-38, 1972.

[2] S. U. M. Khan, M. Al-Shahry, and W. B. Ingler Jr., "Efficient photochemical water splitting by a chemically modified $\mathrm{n}-\mathrm{TiO}_{2}$ ," Science, vol. 297, no. 5590, pp. 2243-2245, 2002.
[3] K. Maeda, K. Teramura, D. Lu et al., "Photocatalyst releasing hydrogen from water," Nature, vol. 440, no. 7082, article 295, 2006.

[4] O. K. Varghese, M. Paulose, T. J. LaTempa, and C. A. Grimes, "High-rate solar photocatalytic conversion of $\mathrm{CO}_{2}$ and water vapor to hydrocarbon fuels," Nano Letters, vol. 9, no. 2, pp. 731737, 2009.

[5] X. Chen and S. S. Mao, "Titanium dioxide nanomaterials: synthesis, properties, modifications and applications," Chemical Reviews, vol. 107, no. 7, pp. 2891-2959, 2007.

[6] T. Ohmori, H. Takahashi, H. Mametsuka, and E. Suzuki, "Photocatalytic oxygen evolution on $\alpha-\mathrm{Fe}_{2} \mathrm{O}_{3}$ films using $\mathrm{Fe}^{3+}$ ion as a sacrificial oxidizing agent," Physical Chemistry Chemical Physics, vol. 2, no. 15, pp. 3519-3522, 2000.

[7] A. Kay, I. Cesar, and M. Grätzel, "New benchmark for water photooxidation by nanostructured $\alpha-\mathrm{Fe}_{2} \mathrm{O}_{3}$ films," Journal of the American Chemical Society, vol. 128, no. 49, pp. 15714-15721, 2006.

[8] Y. Lin, G. Yuan, S. Sheehan, S. Zhou, and D. Wang, "Hematitebased solar water splitting: challenges and opportunities," Energy and Environmental Science, vol. 4, no. 12, pp. 4862-4869, 2011.

[9] S. D. Tilley, M. Cornuz, K. Sivula, and M. Grätzel, "Lightinduced water splitting with hematite: improved nanostructure and iridium oxide catalysis," Angewandte Chemie, vol. 49, no. 36, pp. 6405-6408, 2010.

[10] J. R. Bolton, "Solar photoproduction of hydrogen: a review," Solar Energy, vol. 57, no. 1, pp. 37-50, 1996.

[11] T. Lindgren, H. Wang, N. Beermann, L. Vayssieres, A. Hagfeldt, and S.-E. Lindquist, "Aqueous photoelectrochemistry of hematite nanorod array," Solar Energy Materials and Solar Cells, vol. 71, no. 2, pp. 231-243, 2002.

[12] R. R. Rangaraju, A. Panday, K. S. Raja, and M. Misra, "Nanostructured anodic iron oxide film as photoanode for water oxidation," Journal of Physics D, vol. 42, no. 13, Article ID 135303, 2009.

[13] N. T. Hahn, H. Ye, D. W. Flaherty, A. J. Bard, and C. B. Mullins, "Reactive ballistic deposition of $\alpha-\mathrm{Fe}_{2} \mathrm{O}_{3}$ thin films for photoelectrochemical water oxidation," ACS Nano, vol. 4, no. 4, pp. 1977-1986, 2010.

[14] S. Kumari, A. P. Singh, S. Sonal et al., "Spray pyrolytically deposited nanoporous $\mathrm{Ti}^{4+}$ doped hematite thin films for efficient photoelectrochemical splitting of water," International Journal of Hydrogen Energy, vol. 35, no. 9, pp. 3985-3990, 2010.

[15] N. T. Hahn and C. B. Mullins, "Photoelectrochemical performance of nanostructured Ti- and Sn-doped $\alpha-\mathrm{Fe}_{2} \mathrm{O}_{3}$ photoanodes," Chemistry of Materials, vol. 22, no. 23, pp. 6474-6482, 2010.

[16] I. Cesar, K. Sivula, A. Kay, R. Zboril, and M. Grätzel, "Influence of feature size, film thickness, and silicon doping on the performance of nanostructured hematite photoanodes for solar water splitting," Journal of Physical Chemistry C, vol. 113, no. 2, pp. 772-782, 2009.

[17] I. Cesar, A. Kay, J. A. G. Martinez, and M. Grätzel, “Translucent thin film $\mathrm{Fe}_{2} \mathrm{O}_{3}$ photoanodes for efficient water splitting by sunlight: nanostructure-directing effect of Si-doping," Journal of the American Chemical Society, vol. 128, no. 14, pp. 4582-4583, 2006.

[18] V. M. Aroutiounian, V. M. Arakelyan, G. E. Shahnazaryan, H. R. Hovhannisyan, H. Wang, and J. A. Turner, "Photoelectrochemistry of tin-doped iron oxide electrodes," Solar Energy, vol. 81, no. 11, pp. 1369-1376, 2007. 
[19] Y. Ling, G. Wang, D. A. Wheeler, J. Z. Zhang, and Y. Li, "Sndoped hematite nanostructures for photoelectrochemical water splitting," Nano Letters, vol. 11, no. 5, pp. 2119-2125, 2011.

[20] J. Cai, S. Li, Z. Li, J. Wang, Y. Ren, and G. Qin, "Electrodeposition of Sn-doped hollow $\alpha-\mathrm{Fe}_{2} \mathrm{O}_{3}$ nanostructures for photoelectrochemical water splitting," Journal of Alloys and Compounds, vol. 574, pp. 421-426, 2013.

[21] X. Meng, G. Qin, W. A. Goddard et al., “Theoretical understanding of enhanced photoelectrochemical catalytic activity of Sn-doped hematite: anisotropic catalysis and effects of morin transition and sn doping," The Journal of Physical Chemistry C, vol. 117, no. 8, pp. 3779-3784, 2013.

[22] J. H. W. de Wit, A. F. Broersma, and M. Stroband, "Surface instability and nonstoichiometry of $\alpha-\mathrm{Fe}_{2} \mathrm{O}_{3}$," Journal of Solid State Chemistry, vol. 37, no. 2, pp. 242-247, 1981.

[23] S. Shen, P. Guo, D. A. Wheeler et al., "Physical and photoelectrochemical properties of $\mathrm{Zr}$-doped hematite nanorod arrays," Nanoscale, vol. 5, no. 20, pp. 9867-9874, 2013.

[24] B. Yang, G. Qin, W. Pei, S. Li, Y. Ren, and S. Ishio, "effect of phosphor addition on intergranular exchange coupling of CoPt thin films," Journal of Materials Science and Technology, vol. 27, no. 5, pp. 398-402, 2011.

[25] X. Wen, S. Wang, Y. Ding, Z. Lin Wang, and S. Yang, "Controlled growth of large-area, uniform, vertically aligned arrays of $\alpha$ $\mathrm{Fe}_{2} \mathrm{O}_{3}$ nanobelts and nanowires," Journal of Physical Chemistry B, vol. 109, no. 1, pp. 215-220, 2005.

[26] Q. Wei, Z. Zhang, Z. Li, Q. Zhou, and Y. Zhu, "Enhanced photocatalytic activity of porous $\alpha-\mathrm{Fe}_{2} \mathrm{O}_{3}$ films prepared by rapid thermal oxidation," Journal of Physics D, vol. 41, no. 20, Article ID 202002, 2008.

[27] J. S. Jang, J. Lee, H. Ye, F.-R. F. Fan, and A. J. Bard, "Rapid screening of effective dopants for $\mathrm{Fe}_{2} \mathrm{O}_{3}$ photocatalysts with scanning electrochemical microscopy and investigation of their photoelectrochemical properties," Journal of Physical Chemistry C, vol. 113, no. 16, pp. 6719-6724, 2009.

[28] K. Sivula, R. Zboril, F. Le Formal et al., "Photoelectrochemical water splitting with mesoporous hematite prepared by a solution-based colloidal approach," Journal of the American Chemical Society, vol. 132, no. 21, pp. 7436-7444, 2010.

[29] R. Morrish, M. Rahman, J. M. D. MacElroy, and C. A. Wolden, "Activation of hematite nanorod arrays for photoelectrochemical water splitting," ChemSusChem, vol. 4, no. 4, pp. 474-479, 2011.

[30] J. Tauc, R. Grigorovici, and A. Vancu, "Optical properties and electronic structure of amorphous germanium," Physica Status Solidi B, vol. 15, pp. 627-637, 1966.

[31] J. D. Bryan and D. R. Gamelin, "Doped semiconductor nanocrystals: synthesis, characterization, physical properties, and applications," Progress in Inorganic Chemistry, vol. 54, pp. 47-126, 2005.

[32] K. D. Sieber, C. Sanchez, J. E. Turner, and G. A. Somorjai, "Preparation, characterization and photoelectronic properties of germanium-substituted $\mathrm{Fe}_{2} \mathrm{O}_{3}$ single crystals," Journal of the Chemical Society, Faraday Transactions 1, vol. 81, no. 5, pp. 12631274, 1985.

[33] P. Liao, M. C. Toroker, and E. A. Carter, "Electron transport in pure and doped hematite," Nano Letters, vol. 11, no. 4, pp. 17751781, 2011

[34] J. Z. Jiang, R. Lin, K. Nielsen, S. Mørup, D. G. Rickerby, and R. Clasen, "Interstitial positions of tin ions in $\alpha$-( $\left(\mathrm{Fe}_{\text {rich }} \mathrm{Sn}\right)_{2} \mathrm{O}_{3}$ solid solutions prepared by mechanical alloying," Physical Review B, vol. 55, no. 22, pp. 14830-14835, 1997.
[35] M. Sorescu, L. Diamandescu, D. Tarabasanu-Mihaila, V. S. Teodorescu, and B. H. Howard, "Hydrothermal synthesis and structural characterization of $(1-\mathrm{x}) \alpha-\mathrm{Fe}_{2} \mathrm{O}_{3}-\mathrm{xSnO}_{2}$ nanoparticles," Journal of Physics and Chemistry of Solids, vol. 65, no. 5, pp. 1021-1029, 2004.

[36] H. L. Sanchez, H. Steinfink, and H. S. White, "Solid solubility of ge, si, and $\mathrm{mg}$ in $\mathrm{Fe}_{2} \mathrm{O}_{3}$ and photoelectric behavior," Journal of Solid State Chemistry, vol. 41, no. 1, pp. 90-96, 1982. 

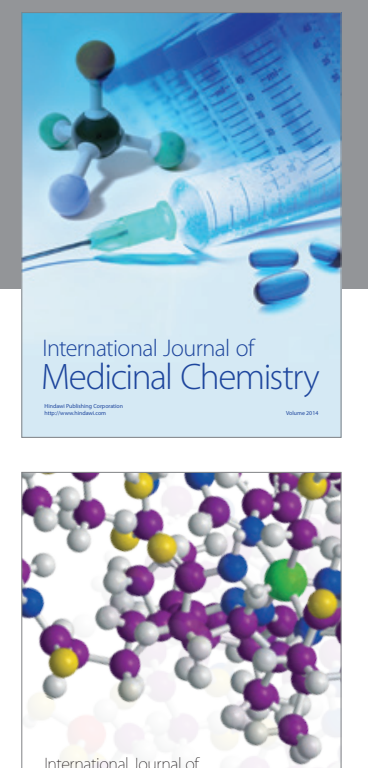

\section{Carbohydrate} Chemistry

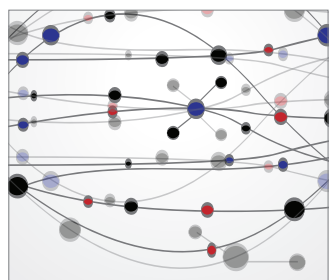

The Scientific World Journal
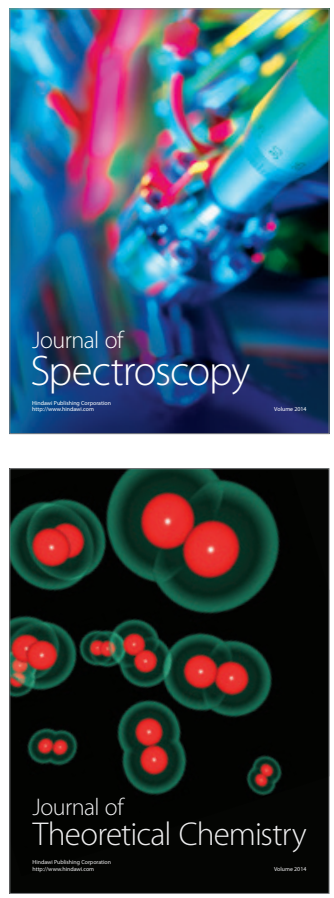
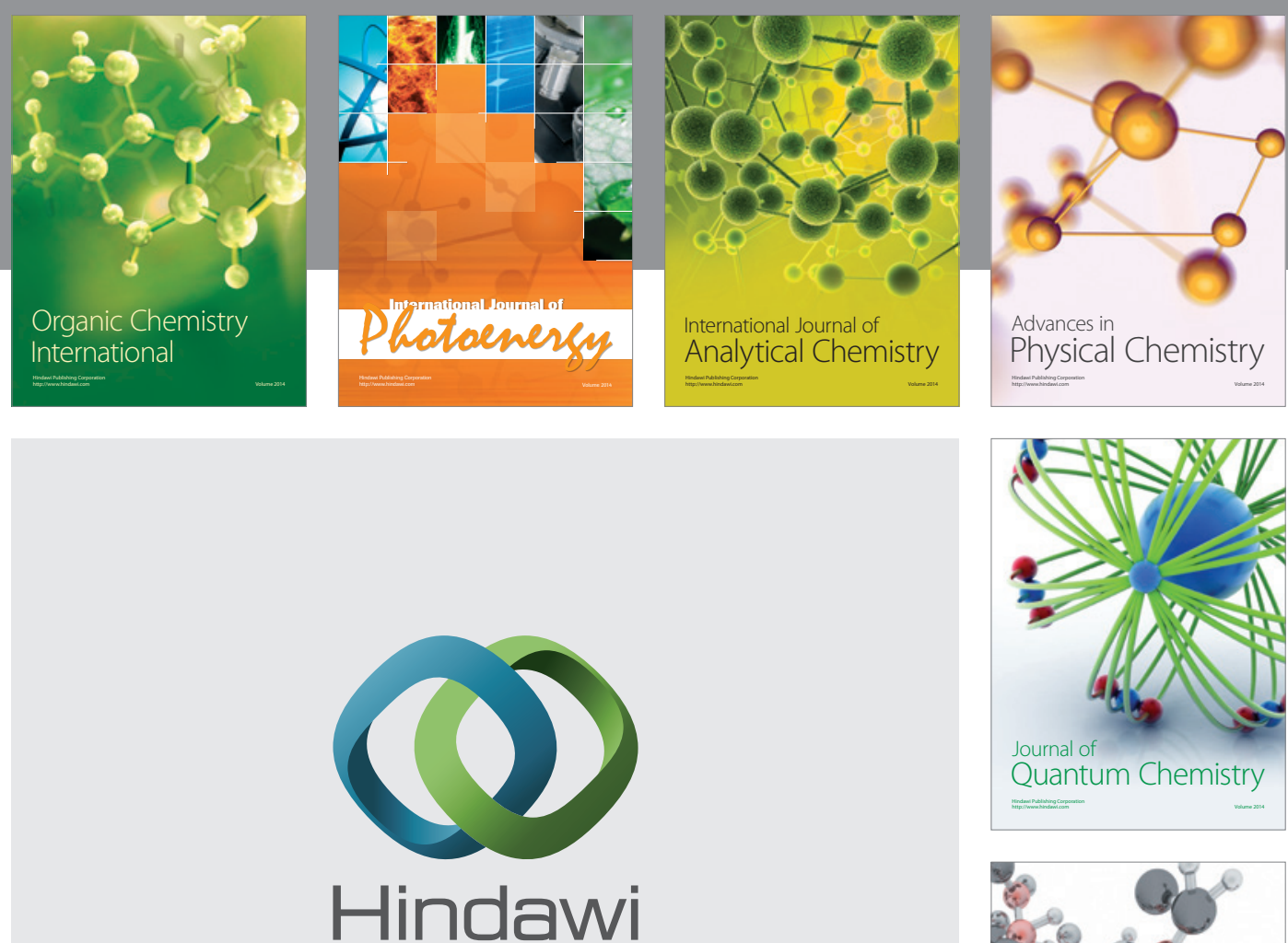

Submit your manuscripts at

http://www.hindawi.com

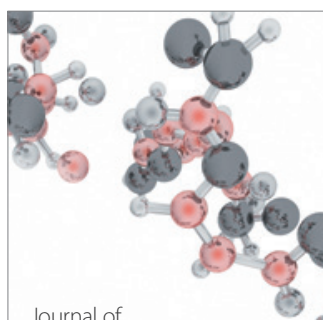

Analytical Methods

in Chemistry

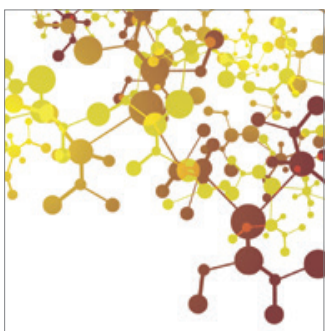

Journal of

Applied Chemistry

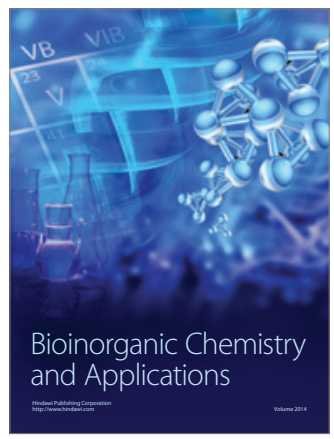

Inorganic Chemistry
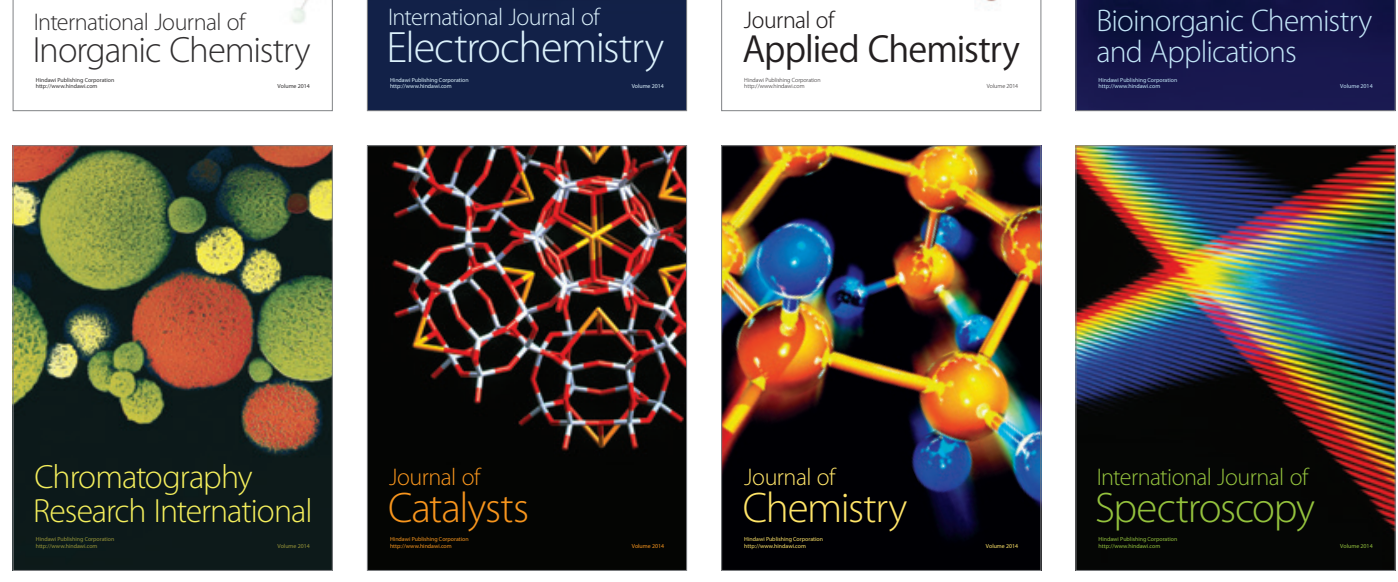